\title{
Dispositivos Artísticos e Vigilantes: as Estratégias Estéticas da Software Art
}

\author{
Liliane da Costa Nascimento ${ }^{1}$ \\ ECO/UFRJ
}

\begin{abstract}
Resumo: Este artigo parte da premissa de que um segmento significativo da produção artística contemporânea abrigado sob a égide da software art se refere à busca por re-agenciar a funcionalidade segmentada dos softwares com que interagimos cotidianamente, de modo a elucidar os subtextos políticos e estéticos inerentes a seu uso. Desta forma, nos dedicaremos aqui à análise de um projeto em especial, o Carnivore PE, que nasceu de uma subversão do software homônimo, usado pelo Federal Bureau of Investigation (FBI) para vigilância eletrônica. Em um primeiro momento identificaremos o tipo de vigilância tematizado por estas práticas. Em seguida buscaremos, através do estudo dos clientes do Carnivore PE, as implicações e estratégias estéticas implícitas à passagem dos dispositivos vigilantes aos artísticos.
\end{abstract}

Palavras-chave: Software art; dispositivo; vigilância.

Abstract: This article considers that a significative segment of the contemporary artistic production known as software art seek to re-elaborate the segmented functionality of the softwares with we interact frequently, elucidating the political and aesthetic subtexts inherents to its use. So, we dedicated ourselves to the analysis of a single project, the Carnivore PE that emerged from a subversion of a homonym software, used by the Federal Bureau of Investigation (FBI) to electronic surveillance. At first, we will identificate the kind of vigilance theses practices chose as theme. Then, we will search, through the analyze of Carnivore PE clients, the implications and strategies implicit to the passage from the vigilants to the artistics "dispositifs".

Key words: Surveillance; "dispositif"; surveillance.

\footnotetext{
${ }^{1}$ Bacharel em jornalismo pela Universidade Federal de Juiz de Fora (UFJF). Ex- bolsista do Programa de Educação Tutorial (PET/SESu/MEC) da Faculdade de Comunicação da Universidade Federal de Juiz de Fora (PET-Facom). Atualmente, mestranda em "Comunicação e Cultura" na linha "Novas Tecnologias e Estéticas" do PPGCOM/ECO/UFRJ e bolsista CAPES.
} 
Résumé: Cet article présuppose qu'un segment significatif de la production artistique contemporaine - software art - se refére à la recherche d'une réorganisation de la fonctionalité segmentée des logiciels dont on s'en sert au jour le jour de maniére à élucider les soustextes politiques et esthétiques inhérents à cet usage. Ainsi, dans ce travail nous analyserons un projet, à savoir, le Carnivore PE, né d'une subversion du logiciel homonyme utilisé par le Federal Bureau of Investigation (FBI) pour la surveillance electronique. $D^{\prime}$ abord nous identifierons le type de surveillance utilisé par ce pratiques, et ensuite nous chercherons, à travers l'étude des utilisateurs de Carnivore PE, les implications et les stratégies esthétiques implicite dans le passage des dispositifs surveillantes aux dispositifs artistiques.

Mots-clés: Software art; dispositf; surveillance.

Resumen: Eso artículo parte de la premisa de que un segmento significativo de la producción artística contemporánea, acogido sob la égida de software art, se refire a la búsqueda por reagenciar la funcionalidad segmentada de los softwares con los que interaccionamos en el cotidiano, de modo a aclarar los subtextos políticos e estéticos inerentes a su uso. Así, nosotros nos dedicaremos a la investigación de un proyeto en especial, el Carnivore PE, que nasció de una subversión del software homónimo, utilizado por el Federal Bureau of Investigation (FBI) para la vigilancia eletrónica. En un primer momento identificaremos el tipo de vigilancia tematizado por estas prácticas. En seguida buscaremos, a través del estudio de los clientes de el Carnivore $P E$, las implicaciones y estrategias estéticas implícitas al pasaje de los dispositivos vigilantes al artístico.

Palabras-clave: Software art; dispositivo; vigilancia.

\section{Introdução}

O cenário que se delineia nas páginas deste trabalho tem, de um lado, as controversas tecnologias de vigilância que emergem no ciberespaço, e de outro, as transformações - menos recentes do que muitos apontam - que colocam em curso reconfigurações profundas no campo da arte. Elegemos como lugar de investigação um casamento à primeira vista curioso e improvável destes elementos: a software art, segmento da produção artística contemporânea que age através da produção de softwares experimentais e da subversão de aplicações computacionais específicas, buscando elucidar seus subtextos políticos através de propostas estéticas por vezes sarcásticas e inusitadas. Se diferenciando fundamentalmente de grande parcela da arte digital contemporânea, a software art não concebe o software ou o código como 
ferramentas meramente técnicas, que devem ser transparentes ao usuário. Ao contrário, ela se interessa diretamente pelas implicações das estruturas codificadas, e visa

questionar software e código como cultura, e questionar a cultura como implementada no software. Para tanto, ela desenvolve "softwares experimentais" (...), que não apenas geram superfícies abstratas, mas que criticamente investigam os impactos tecnológicos, culturais ou sociais do software. ${ }^{2}$

Neste sentido, nosso objetivo é investigar as possibilidades desta estética no desenvolvimento de propostas artísticas que possuem como alvo os dispositivos de vigilância no ciberespaço. Para tanto, consideraremos um projeto em especial: o Carnivore PE, buscando, através da análise de seus clientes, as estratégias usadas para re-agenciar os pressupostos basilares dos dispositivos de vigilância existentes no ciberespaço. Assim, em um primeiro momento, nosso objetivo é identificar a que tipo de vigilância estas práticas se dirigem, para assim, realizar apontamentos sobre a diagramação específica que este projeto, em sua totalidade, confere às formas assumidas pelo poder nos ambientes digitais. Desta forma, acreditamos que esta análise pode revelar elementos e estratégias de uma possível estética para software art.

\section{Afinal de contas, o que é um dispositivo?}

Segundo Bentes (2007), a teoria dos dispositivos foi formulada nos anos 70, em um contexto fortemente marcado pelo estruturalismo e pelas estreitas relações entre o cinema e a psicanálise. Ela relata que em 1975, Jean Louis Baudry, se dedicando à teoria do espectador cinematográfico, propôs pensar o próprio cinema como dispositivo, o que implicava reconhecer e desnudar as características que regulam as relações - mentais, temporais e espaciais - entre o espectador e a obra3. Assim, esta noção nasce designando não apenas o aparato técnico, mas o modelo perceptivo e mental implícito a seu funcionamento. Da década de 80 aos dias atuais, no entanto, a teoria dos dispositivos foi deslocada por autores diversos para outros contextos. De modo geral, como nos assinala Bentes,

\footnotetext{
${ }^{2}$ ARNS, Inke: 2005, p. 4.

3 Cf. BENTES, Ivana: 2007, p. 5 . 
ao ultrapassar o plano dos significados e conteúdos, dando ênfase em aspectos formais, técnicos, espaciais, que configuram o sentido, o conceito de dispositivo se tornou decisivo para se pensar uma série de campos emergentes, como a videoarte, as vídeoinstalações, a arte telemática, as estéticas e narrativas extraídas do campo da comunicação ou os usos estéticos e sociais da Internet, celular, GPS, web-câmeras, sensores e câmeras de vigilância, programas, redes e sistemas de sociabilidade 4 .

Para o propósito deste trabalho, recuperaremos a passagem dos dispositivos vigilantes aos artísticos a partir do recorte de alguns aspectos definidores desta noção na obra de diferentes autores. O ponto de partida é a formulação de Michel Foucault, tal como explicitada no primeiro volume da obra "História da Sexualidade" (1988). Ao dispensar a idéia de uma "teoria" do poder em detrimento de uma "analítica" capaz de abordar sua positividade, Foucault recusa uma lógica binária que reduza seus mecanismos de funcionamento a proibido e permitido, lícito e ilícito. Neste sentido, ele analisa a formação de um certo tipo de saber sobre o sexo, "não em termos de repressão ou de lei, mas em termos de poder 5 ". Assim, o autor recupera o processo histórico de passagem dos dispositivos de aliança aos dispositivos de sexualidade a partir do século XVIII. Em síntese, enquanto os dispositivos de aliança tinham seu foco no vínculo entre parceiros com status definido, se baseando nas hierarquias do permitido e do proibido para produzir e manter a trama de relações que sustentava a lei, o dispositivo de sexualidade buscava agir sobre as sensações do corpo e sobre a qualidade dos prazeres, atuando segundo formas móveis, plurais e inventivas de controle ${ }^{6}$.

Assim, ressaltamos que, na obra de Foucault, os dispositivos estão intrinsecamente relacionados a formas de controle e poder. E para o autor, o poder deve ser compreendido, sobretudo, como a "multiplicidade de correlações de força imanentes ao domínio onde se exercem e constitutivas de sua organização7". Desta forma, os dispositivos aludem ao engendramento de estratégias de saber e de poder em contextos particularmente delimitados. Eles não se referem a uma "realidade subterrânea" a ser revelada, mas a uma complexa "rede de superfície", formada por elementos táticos, mecanismos de constrição, formas de controle e técnicas

4 BENTES, Ivana: 2007, p. 6.

5 FOUCAULT, Michel: 1988, p. 88.

${ }^{6}$ Cf. Ibidem, p. 100-101.

7 Ibidem, p. 88. 
conjeturais que se articulam segundo vinculações determinadas e que respondem a objetivos específicos ${ }^{8}$.

Neste sentido, a partir de um resgate das proposições foucaultianas, Gilles Deleuze (1988) define um dispositivo como um conjunto multilinear, composto de linhas de natureza diferente ${ }^{9}$. Estas linhas não circundam ou delimitam os diferentes sistemas como parcelas independentes, delimitadas e homogêneas. Ao contrário, trata-se de multiplicidades compostas por linhas ativas que seguem processos em desequilíbrio - linhas que ora se afastam, ora se aproximam, tensionadas pelos objetos visíveis, pelos enunciados formulados e pelos poderes, saberes e subjetividades em jogo. Segmentares ou de fuga, molares ou moleculares, elas compõem, atravessam, permeiam e colocam em movimento os dispositivos, cartografias a serem desembaraçadas, decifrando os pólos e as formas assumidas pelo poder. Trata-se de máquinas de visibilidade e enunciação, que comportam linhas de força e também linhas de subjetivação. Estas últimas engendrariam processos de ruptura - ligados marcadamente à ordem da criação - que preparariam a passagem de um dispositivo a outro: "as produções de subjetividade escapam dos poderes e saberes de um dispositivo para se reinvestir em outro, sob outras formas a serem ainda concebidas ${ }^{10}$ ".

Já no que diz respeito aos dispositivos artísticos, Anne-Marie Duguet ressalta a importância da invenção de dispositivos de captação, produção e percepção da imagem para a videoarte. Neste contexto, a autora pontua:

Ao mesmo tempo máquina e maquinação (segundo a acepção da méchanè grega) todo dispositivo visa produzir efeitos específicos. Este agenciamento das peças de um mecanismo é um sistema criador, que estrutura a experiência sensível a cada vez de maneira específica. Mais que uma simples organização técnica, o dispositivo coloca em jogo diferentes instâncias enunciativas ou figurativas, e emprega as situações institucionais enquanto processos de percepção ${ }^{11}$.

Assim, para a autora, os dispositivos se referem à invenção de sistemas com características peculiares que experimentam, de um lado, restrições de ordem técnica

\footnotetext{
8 Os termos "realidade subterrânea" e "rede de superfície" estão em FOUCAULT, Michel: 1988, p. 100.

9 Cf. DELEUZE, Gilles: 1988, p. 185.

${ }^{10}$ Ibidem, 1988, p. 188.

${ }^{11}$ DUGUET, Anne-Marie: 2002, p. 21.
} 
que submetem suas capacidades, e de outro, as limitações impostas pelas próprias regras que o dispositivo sugere. Isto porque, como exigência do próprio processo de identificação dos dispositivos por parte dos espectadores, não somente expectativas, mas também limitações, ligadas às narrativas e explorações estéticas possíveis definem - e pré-definem - a forma de uso dos meios destas máquinas ${ }^{12}$.

\section{Os dispositivos da vigilância contemporânea}

A explosão dos mecanismos de poder para fora dos limites das instituições marca a passagem das sociedades disciplinares às sociedades de controle. Nesta transição se conjugam linhas de continuidade e ruptura, cuja análise nos permite compreender melhor os dispositivos contemporâneos de vigilância existentes no ciberespaço. Inicialmente, nas sociedades disciplinares, novas práticas de poder descentralizado elegem os dispositivos ópticos como suas máquinas de vigilância ideais. Assim, a visibilidade - encarnada no modelo arquitetônico do panóptico, que se coloca como síntese e utopia do controle disciplinar - investe os indivíduos comuns e, mais ainda, os desviantes, tornando visíveis os espaços internos e hierarquizando o regime do visível em um modelo centro/periferia que funciona a partir da dissimetria entre o ver e o ser visto. Desta forma, a indecidibilidade do olhar vigilante promove a interiorização do olho do poder, produzindo uma ordem social programável que resulta na busca dos indivíduos pelo ideal da norma (Foucault, 1983).

Já no ciberespaço, a presença de uma instância central que age em espaços fechados é substituída por um jogo descentralizado e disperso, que acontece em espaços virtuais, i.e., informacionais. Esta dimensão informacional, além do controle exercido pelo olhar, pode ser relacionada à dimensão do saber que buscava objetivar os indivíduos nas sociedades disciplinares ${ }^{13}$. Foucault (1983) se refere aos exames, acumulações documentais, técnicas de coleta e registros de dados que tornavam as instituições lugares propícios para a produção de conhecimento sobre os indivíduos. Esta coleta de dados sobre suas características, competências, falhas e performances visava subsidiar a classificação e a dedução de médias e normas que regulariam todo o corpo social. E para a vigilância digital, consideradas as devidas rupturas, esta

\footnotetext{
${ }^{12}$ Cf. Ibidem, p. 22-3.

${ }_{13}$ Cf. FOUCAUT, Michel: 1983, p. 166-9.
} 
dimensão informacional se torna preponderante, uma vez que ela é parte integrante - imanente e inerente - ao próprio dispositivo de comunicação dos indivíduos, que deixam, a todo o momento, rastros imateriais de suas ações nos espaços virtuais.

Desta forma, podemos afirmar que, "em linhas gerais, o dispositivo de vigilância digital tem três elementos centrais: a informação, os bancos de dados e os perfis computacionais (profiles) ${ }^{14}$ ", unificados pelo código e pelo software enquanto instâncias efetivadoras do poder vigilante. Neste dispositivo, a coleta anônima de dados - que se dá em nível infra-individual - compõe bancos de dados, que permitirão o armazenamento e principalmente o tratamento da informação para a produção de conhecimento sobre os indivíduos e/ou grupos. Nestes bancos, que abrigam dados em categorias específicas (de gênero, de faixa etária, profissionais, financeiras, biológicas, etc.), atuam algoritmos responsáveis pela composição de perfis, verdadeiras tecnologias de observação antes do fato ${ }^{15}$, que agem de maneira preditiva e performativa, visando antecipar tendências, gostos, preferências, interesses. Assim, a vigilância no ciberespaço não visa remediar ou curar os desviantes, mas sim, projetar antevisões e instaurar realidades possíveis a partir de sua projeção. Desta forma, o perfil não é verdadeiro nem falso: ele é da ordem da simulação. Assim como o código, ele é performativo e busca efetivar aquilo que enuncia, intervindo no campo das ações possíveis ${ }^{16}$.

Neste sentido, "essas tecnologias simulam a vigilância na medida em que elas precedem e multiplicam os meios de observação ${ }^{17}$ ”. E a simulação aqui não se confunde com ilusão: ela se refere à atuação no regime do tempo, à antecipação de um futuro possível e à produção de uma hiperrealidade, na qual o grau de perfeição da simulação faz com que distingui-la da realidade deixe de fazer sentido. Assim, a vigilância é identificada com uma máquina que, ao invés de se restringir à documentação e registro de fatos verdadeiros, se ocupa em simular a factividade dos regimes de possível. Sua operação instaura, desta forma, um estado de reversibilidade entre vigias e vigiados, verdade e ficção, infratores e homens da lei.

\footnotetext{
14 BRUNO, Fernanda: 2006, p. 154.

15 Cf. BOGARD, William: p. 27.

16 Um bom exemplo pode ser dado pelos softwares agentes como os da livraria virtual amazon.com, que antecipam nossas possibilidades de consumo aos nos apresentar produtos que até então desconhecíamos. CF BRUNO, Fernanda: 2006, p. 156.

17 BOGARD, William: p. 27.
} 
Todas estas diferenças se reduzem, assim, a modulações de trechos de código: nos dispositivos da vigilância contemporânea, o código assume o cobiçado lugar de norma das normas, aquele que instaura e torna efetivas as realidades desejadas pelo poder.

\section{A software art}

Antes de passarmos ao estudo específico ao qual se dedica este artigo, avaliaremos as características do meio particular ao qual as propostas da software art se dirigem: o software. Um software é constituído por algoritmos, conjuntos de instruções formais que estabelecem uma seqüência ordenada e não ambígua de procedimentos. Quando obedecidos, tais comandos resultam numa sucessão finita de ações que objetivam a resolução de um determinado problema. O termo software foi inventado em 1957 pelo matemático Jonh W. Turkey, séculos depois do termo algoritmo, cujas origens remontam à civilização persa do século nono. Assim, o termo software surge justamente referenciado à lógica dos algoritmos abstraídos do suporte da máquina, o que possibilita também uma analogia com a arte conceitual, para a qual deve prevalecer a idéia, independente das técnicas e materiais empregados.

Primeiramente, consideremos o software em seu nível formal, como algoritmos ou conjuntos de instruções lógicas formalizadas em um código. Neste contexto, o código é uma linguagem, pois, além de ser um método de notação formal, possui natureza significante arbitrária e sintaxe própria. Sua especificidade com relação a outras linguagens, no entanto, está justamente em sua execução: a linguagem do código não possui apenas uma função significante ou referencial. Aqui, a palavra comete fatos, ou seja, ela é capaz de criar ou fazer justamente o que enuncia.

Um programa de computador é um projeto e sua execução ao mesmo tempo. (...) A fascinação artística da programação de computadores - e talvez a revelação extasiante de qualquer um que programe pela primeira vez - é a equivalência entre arquitetura e construção, a gratificação instantânea dada uma vez que o conceito é finalizado. A programação quebra, ao que parece, o segundo e o terceiro dos três estágios de um conceito, a notação do conceito e sua execução. ${ }^{18}$

${ }^{18}$ CRAMER, Florian. 2002: p.4. 
Portanto, concluímos que o software não é uma interface transparente, mas um material que permite ou limita a expressão pessoal. Assim como é impossível usar um computador sem programas, não existem dados digitais se não há software. $\mathrm{E}$ a software art se caracteriza justamente por explicitar o papel cultural do software num mundo conectado em rede. Ele define os padrões de comunicação e as regras do fluxo dos negócios em escala global. Deste modo, ele molda também nossas possibilidades de criação e expressão da cultura digital.

A cultura do software é a cultura viva dos programadores e usuários, como participantes ativos de um mundo de - ou mediado pelo software. Em sua essência, ela circunscreve um campo de intensa produção imaterial, no nível da codificação, do uso, da especulação ou reflexão crítica e na periferia cada aspecto da vida humana que, de alguma forma, é orientado ou controlado pelo software. A software art está refletindo as realidades e potenciais dessa cultura. ${ }^{19}$

Assim, teoricamente, apontamos as características conceituais e culturais do código e do software. No entanto, tais aspectos podem ou não estar presentes no contextos dos projetos desenvolvidos sob a égide da software art, o que apenas a avaliação empírica de suas propostas, feita caso a caso, pode apontar. Ressaltamos, no entanto, dois aspectos que aqui nos parecem essenciais: a proximidade das noções de dispositivo e maquinação com a atividade da programação, e a proximidade conceitual entre a performatividade dos perfis e a performatividade do código. No primeiro caso, tal como proposto pela definição de Anne Marie Duguet (2002), consideramos que os agenciamentos específicos não se definem apenas por sua dimensão técnica, embora estejam estritamente relacionados à arrumação das peças de um dado mecanismo. E no segundo, levantamos as relações do dispositivo vigilante com seu aparato técnico. Seria o transbordar desta lógica por vezes quantitativa, por vezes indecidível, certamente analítica ao extremo - inerente ao código e à sua potencialidade de tratar dados - que estaria transbordando para o corpo social e para as práticas vigilantes?

\section{Carnivore PE: os dispositivos da software art}

O projeto analisado nesta seção, a saber, o Carnivore $P E$, usa como ponto de partida a dimensão informacional da coleta e do registro de dados trafegados no

${ }^{19}$ SCHULTZ, Pit. From a closed mailing list discussion. Disponível em <www.rumne.org>. 
ciberespaço. Surgido no contexto de restrição das liberdades individuais no pós 11 de setembro, ele foi produzido pelo Radical Software Group (RSG) ${ }^{20}$ a partir da subversão do software Carnivore, um sniffer ${ }^{21}$ usado pelo Federal Bureau of Investigation (FBI) para vigilância eletrônica ${ }^{22}$. Admitindo que muitos criminosos usam a internet para se comunicar entre si ou com suas vítimas, o FBI o desenvolveu como uma "ferramenta de diagnóstico", composta por um computador de uso geral para a filtragem e coleta de dados e outros para o controle, armazenamento e exame dos dados capturados. À maneira de um grampo que opera nas linhas telefônicas, o sniffer era instalado nos computadores de provedores de acesso americanos e controlado remotamente (exclusivamente por link telefônico). E segundo o FBI, a partir da filtragem de todo o fluxo de dados da rede correspondente, o software capturaria apenas a informação recomendada por uma autorização judicial²3.

O sistema levantou polêmicas na sociedade americana em torno da proteção dos direitos à privacidade na internet, o que levou o Departamento de Justiça americano a contratar o IIT Research Institute para um parecer técnico sobre o software. A conclusão foi de que, no modo limitado, o Carnivore seria capaz de capturar apenas o e-mail e endereço IP dos computadores envolvidos em seções de FTP e HTTP. No modo completo, no entanto, seria possível acessar o conteúdo das mensagens de e-mail, os sites acessados, seções de FTP, conversas de chat, etc. Além disso, os filtros de busca poderiam ser facilmente trocados pelos agentes responsáveis pela operação do software ${ }^{24}$. Isto significaria que não apenas os suspeitos sob investigação judicial seriam inspecionados: eventualmente, qualquer um poderia ser vigiado por este dispositivo e cidadãos comuns seriam automaticamente convertidos em suspeitos de algum crime real ou potencial. Trata-se de uma lógica efetiva, pois a

\footnotetext{
${ }^{20} \mathrm{http}: / / \mathrm{r}-\mathrm{s}-\mathrm{g} . \mathrm{org} /$

${ }^{21}$ Os sniffers são programas capazes de interceptar e armazenar o fluxo de uma rede ou subrede. Sniffers comerciais - amplamente disponíveis no mercado - atuam como ferramentas essenciais para o bom funcionamento da internet, uma vez que permitem realizar diagnósticos do fluxo de dados em uma rede.

$22 \mathrm{O}$ Carnivore surgiu do antigo projeto Omnivore, que começou a ser desenvolvido em fevereiro de 1997 e que foi encerrado oficialmente em junho de 1999, a um custo total de 900.000 dólares. Os testes da fase de desenvolvimento do Carnivore culminaram com a versão 1.2, lançada em setembro de 1999. Com as polêmicas levantadas acerca desta ferramenta, o FBI a renomeou como DSC 1000 em fevereiro de 2001.

${ }^{23}$ A lei americana permite $o$ acesso a comunicações privadas apenas sob a liberação de uma ordem judicial, a despeito do meio em que se passam.

24 Cf. SOBEL, David: 2001, p. 87-8.
} 
vigilância pré-existe à suspeita. Ainda que não seja possível precisar os desvios ocorridos, a própria capacidade técnica do software levanta questionamentos importantes. Afinal, porque ele teria sido desenvolvido com aptidões que não deveriam ser utilizadas?

Desta forma, o coletivo de artistas usou esta ferramenta de vigilância como base para um trabalho inventivo: produzir interfaces diversas - trechos de código denominados clientes - capazes de interpretar o fluxo de dados proveniente do monitoramento de uma rede. "Aperfeiçoando o software do FBI, o Carnivore PE apresenta novas funcionalidades, que incluem: clientes para diagnóstico feitos por artistas, acesso remoto, monitoramento de todos os usuários e de todos os tipos de dados, filtragem por tipo de protocolo e licença para software livre25”. Assim, o RSG produziu um sniffer com código fonte aberto e encorajou artistas da comunidade net.art e pessoas comuns a escreverem seus próprios clientes. Assim, como participante e co-autor, é possível contribuir para o código fonte do sniffer assim como produzir e/ou experimentar os clientes para o software.

Analisando as vinte e quatro interfaces produzidas para o projeto, podemos identificar dois grandes grupos. O primeiro deles reúne os trabalhos que não abordam o tema da vigilância diretamente: elas se concentram em fornecer visualizações para padrões abstratos, sem se preocupar com a identificação (em nível individual ou infra-individual) dos responsáveis pelos fluxos monitorados. Trata-se de subverter a vigilância enquanto forma de controle e poder para fornecer aos interatores conhecimento empírico sobre o próprio funcionamento das redes. Afirmamos aqui, usando a categorização proposta por Manovich (online) ${ }^{26}$, que este primeiro grupo de aplicações se concentra na visualização de dados através da produção de dispositivos pedagógicos e metalingüísticos: elas se apropriam da capacidade de analisar uma rede, implícita aos sniffers, para tornar tangíveis -

\footnotetext{
25 Disponível em http://r-s-g.org/carnivore/about.php.

${ }^{26}$ Como nos coloca Manovich, a visualização de dados diz respeito a situações em que informações que por natureza não são visuais - como o fluxo de dados na internet, $o$ funcionamento dos mercados financeiros, etc. - são convertidas em imagem. Assim, os computadores são, por natureza, máquinas que facilitam a conversão de uma representação em outra a partir de técnicas de mapeamento, possibilitadas pela conversão dos dados em um só código. Cf. MANOVICH, Lev: online.
} 
através de formas visuais e sonoras - a imensa massa de dados que compõe a internet.

Este é o caso de clientes como o Active Metaphor, por exemplo. Interessado no fluxo de dados e não no conteúdo ou nos indivíduos envolvidos nas comunicações que se passam na internet, este cliente decompõe o endereço IP ("aaa.bbb.ccc.ddd") em quatro grupos (“aaa”; 'bbb”; “ccc”; “ddd'), responsáveis, respectivamente, pelas coordenadas $\mathrm{x}, \mathrm{y}, \mathrm{z}$ e pelo grau de transparência de formas geométricas que aparecem na tela a partir dos dados monitorados (além de fornecer também feedback sonoro). Assim, trata-se de tornar sensíveis - visíveis e audíveis - informações que, de outra forma, seriam imperceptíveis. Por outro lado, em uma proposta mais instigante, o History of Art for the Intelligence Community, de Vuk Cosic, promove visualizações não através de gráficos visuais: trata-se de intervir em obras de arte clássicas, o que envolve, por exemplo, usar o número de e-mails recebidos por um usuário para alterar o número de cerejas em uma projeção virtual do quadro "Natureza morta com prato de cerejas" (1885-87), de Paul Cézanne. Desta forma, o jogo propõe, através do questionamento de uma estética plenamente aceita e admirada, o tratamento de práticas políticas inaceitáveis.

O outro grupo discernido no conjunto dos clientes escritos para o Carnivore é o daqueles que - ainda que operem com a visualização de dados, inerente a todas as interfaces elaboradas - buscam tematizar de maneira mais direta os mecanismos, conseqüências e efeitos da vigilância no ciberespaço. Aqui, este fluxo de dados abstrato é re-agenciado em ações que visam identificar e/ou encaixar em perfis os usuários envolvidos nos processos de comunicação monitorados. Um exemplo bem simples pode ser dado pelo World Wall Painters (WWP). Monitorando o fluxo de dados do próprio interator, o cliente oferece uma interface na qual dois personagens pintam em um muro a bandeira dos dois países onde se localizam as máquinas envolvidas em uma comunicação via internet. Assim, se acesso um site cujo servidor está localizado na Suécia, os personagens pintarão a bandeira correspondente ao lado da brasileira. Desta forma, vemos que, em uma abordagem ainda inicial, este cliente busca identificar o país onde se situam os indivíduos e máquinas que se comunicam na rede. 
De maneira semelhante, o cliente JJ opera uma entidade visual anônima, que exibe expressões faciais diversas em conformidade com os sentimentos relacionados ao conteúdo monitorado. Depois que o usuário instala o cliente em sua própria máquina, os dados monitorados pelo Carnivore são cruzados com duas bases de dados provenientes de estudos no campo da Psicologia: uma composta pelas expressões faciais universais de Ekman and Friesen ${ }^{27}$ e outra pelo dicionário Linguistic Inquiry and Word Count ( $L I W C^{28}$ ), de Pennebaker, Francis, \& Booth, que classifica as associações emocionais comuns a uma série de palavras. $\mathrm{O}$ cliente extrai uma palavra de cada pacote trafegado, e no caso de ela bater com a base de dados do LIWC, expressões faciais são mostradas pela entidade facial. Este tratamento estatístico do conteúdo emocional da rede monitorada reconstrói metaforicamente e ironiza o procedimento de composição dos perfis computacionais (de caráter infraindividual), categorizando os sentimentos não dos indivíduos que comunicam, mas do conteúdo trafegado.

Esta abordagem dos perfis também está presente no Police State, cliente que visa reverter o fluxo da vigilância contra o próprio aparelho policial. Nas instalações do projeto, o monitoramento de redes buscava palavras-chave nos pacotes trafegados. No caso destas coincidirem com as existentes em bancos de dados contendo palavras relacionadas ao terrorismo, o código policial correspondente (como 10-79 para ameaça de bomba ou 1000 para acidentes com aviões) era disparado para 20 carrinhos de controle remoto, que executavam uma movimentação coreografada segundo o código informado. Assim, os perfis usados pela polícia são revertidos, com a mesma performatividade, na criação de um mundo simulado em que estes dados são usados para controlar a própria polícia.

Desta forma, concluímos que os clientes analisados realizam uma reversão do fluxo de vigilância - seja em prol dos interatores (para a experiência da visualização de dados) ou fazendo com que ele se volte contra os próprios mecanismos do poder. Ainda que pouca informação esteja disponível acerca dos filtros de busca e dos exames procedidos nos dados obtidos pelo software do FBI, sabemos que, de certa forma, ele já trazia implícito o monitoramento eletrônico, a

\footnotetext{
${ }_{27}$ Cf. <http://www.paulekman.com/>.

${ }^{28}$ Cf. <http: //www.liwc.net $>$.
} 
produção de bancos de dados e o exame da informação obtida. Além disso, o uso de filtros de busca que correspondam a um determinado tipo de suspeito se refere a perfis específicos, ainda que não se saiba se eles foram produzidos por procedimentos idênticos àqueles responsáveis pela produção dos perfis computacionais. Em todos os casos, a indecidibilidade e o caráter simulado da vigilância contemporânea, de certa forma, está presente software do FBI: se o software tem a capacidade de realizar buscas ampliadas, que não se referem apenas a alvos específicos, todos são convertidos em suspeitos - se isto é verdadeiro ou falso, não importa. Em todos os casos, a vigilância será performativa e efetiva.

E quanto aos clientes, outro aspecto que vale ressaltar é a relação estabelecida entre interação e controle. Podemos identificar que os projetos artísticos que partem do monitoramento de uma rede que não a do próprio usuário o colocam como mero espectador, fadado a assistir passivamente os efeitos da vigilância em algum ponto qualquer da internet. Ao contrário, nos casos em que o cliente parte do monitoramento do fluxo de dados da máquina do próprio usuário - ou seja, nos casos em que o vigiado se torna, ao mesmo tempo, um vigia voluntariamente vigiado por si próprio - é que a interação com os clientes se torna possível. Nestes casos, o usuário pode experimentar acessar a internet de várias formas, buscando, em cada caso, o feedback dado pelo projeto para estas diferentes ações de vigilância. Assim, os rituais pré-programados da vigilância são substituídos pela liberdade das interações possíveis em uma obra aberta e a vigilância enquanto atividade ilícita e secreta se torna matéria artística, potencialidade estética a ser explorada.

\section{Implicações estéticas do processo de subversão}

A passagem dos dispositivos vigilantes aos artísticos, no caso analisado, se coloca como forma de resistência a um estado configurado de poder. Reafirmando a software art enquanto máquina conceitual, esta passagem se dá através da construção de espaços outros: se as regras inerentes aos dispositivos vigilantes se confundem e estão implícitas ao funcionamento do dispositivo comunicacional, elas podem ser reagenciadas de em favor daqueles que a controlam. E isto é possível porque a software art possui como matéria prima o código, e a performatividade como valor estético primordial: o código não se resume à sua forma escrita; ele é, ao mesmo tempo, 
conceito e execução. A software art - ao se concentrar no processo e não nos resultados possíveis - identifica a informação como tradutor universal e trabalha exacerbando a todo o momento as regras de funcionamento atuais e virtuais de seus próprios dispositivos. Assim, o espaço informacional implicado (e complicado pelas dobras sucessivas propostas pelo encadeamento dos elementos constituintes e das linhas de força que o compõem); a distribuição e agenciamento dos dados e das possibilidades técnicas do programa produzido e/ou utilizado; a maneira como a obra requisita física e psicologicamente o espectador; todos estes fatores são constitutivos de um processo através do qual um dispositivo é reorganizado e deslocado em relação a sua posição anterior. Assim, bancos de dados, estruturas codificadas, perfis e mesmo a dimensão temporal da vigilância - com sua natureza simulada e performativa - ganham estruturas adicionais e passam a servir a outros objetivos. Na software art, este re-agenciamento provoca uma espécie de “desaceleração” na percepção que cotidianamente apresentamos dos softwares com os quais interagimos, dilatando aspectos silenciosos, ao mesmo tempo implícitos a seu uso e transparentes aos seus usuários. Assim, trata-se de criar um espaço penetrável para a existência ampliada e para o reconhecimento destas situações relacionais, expostas através de confrontos entre duas ficções possíveis que trazem subjacentes outras tantas imagináveis - e inimagináveis: se a vigilância é uma simulação possível, porque não escrever outras? Desta forma, a interação dos participantes se torna o lugar de desvelamento da hiper-realidade e do próprio dispositivo - ela promove o conhecimento do dispositivo vigilante através da exploração da obra e da compreensão dos mecanismos de funcionamento do próprio dispositivo artístico: o controle se torna uma questão de interação, e é subvertido pela codificação de uma estrutura perceptiva para a qual tudo pode ser simulado. 


\section{Referências Bibliográficas}

ARNS, I. 2005. Code as performative speech act. Artnodes [online]. UOC. Disponível em: http://www.uoc.edu/artnodes/eng/arnso505.pdf . Acesso em: 26 mar. 2006.

BENTES, Ivana. O devir estético do capitalismo cognitivo. In: Encontro Anual da Associação Nacional de Programas em Pós-graduação em Comunicação (Compós), 16., Curitiba, 2007. Anais eletrônicos... Disponível em: < http://www.compos.org.br/data/biblioteca_228.pdf?PHPSESSID=631ff6cc9 50a4e6c74eb433163b2f73e>. Acesso em: 12 jul. 2007.

BRUNO, Fernanda. Dispositivos de vigilância no ciberespaço: duplos digitais e identidades simuladas. Revista Fronteiras, São Leopoldo, v. 8, n. 2, p. 152-9, mai./ago., 2006.

BOGARD, William. The simulation of surveillance: hypercontrol in telematic societies. Cambridge: Cambridge University Press, 1996.

CRAMER, Florian (2002). Concepts, notations, software, art [online]. Disponível em:

http://userpage.fuberlin.de/ cantsin/homepage/writings/software_art/conc ept_notations/concepts_notations_software_art.html. Acesso em: 23 abril 2006.

DELEUZE, Gilles. Qu'est ce qu'un dispositif. In: Michel Foucault philosophe. Paris: Seuil, 1988.

DUGET, Anne-Marie. Déjouer l'image: creations électroniques et numériques. Nîmes: Éditions Jacqueline Chambon, 2002.

FOUCAULT, Michel. Vigiar e punir. Petrópolis: Vozes, 1983.

. História da sexualidade I: a vontade de saber. Rio de Janeiro: Edições Graal, 1988.

MANOVICH, Lev. O excesso de dados e o belo. Disponível em: $<$ http://www.cibercultura.org.br/tikiwiki/tiki-

read_article.php?articleId=18\&highlight=\%22manovich\%22> Acesso em 18 jun. 2006.

SOBEL, David L. Will Carnivore devour online privacy? Computer, v. 34, n. 5, p. 878, mai., 2001. 